\title{
Edwidge Danticat (dir.), Haïti noir
}

\section{Emanuela Cacchioli}

\section{(2) OpenEdition}

\section{Journals}

\section{Edizione digitale}

URL: http://journals.openedition.org/studifrancesi/2317

DOI: $10.4000 /$ studifrancesi.2317

ISSN: 2421-5856

\section{Editore}

Rosenberg \& Sellier

\section{Edizione cartacea}

Data di pubblicazione: 1 aprile 2014

Paginazione: 197-198

ISSN: 0039-2944

\section{Notizia bibliografica digitale}

Emanuela Cacchioli, «Edwidge Danticat (dir.), Haïti noir », Studi Francesi [Online], 172 (LVIII | I) | 2014

online dal 01 avril 2014, consultato il 18 septembre 2020. URL : http://journals.openedition.org/ studifrancesi/2317 ; DOI : https://doi.org/10.4000/studifrancesi.2317

\section{Questo documento è stato generato automaticamente il 18 settembre 2020.}

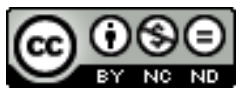

Studi Francesi è distribuita con Licenza Creative Commons Attribuzione - Non commerciale - Non opere derivate 4.0 Internazionale. 


\title{
Edwidge Danticat (dir.), Haïti noir
}

\author{
Emanuela Cacchioli
}

\section{NOTIZIA}

EDWIDGE DANTICAT (dir.), Haïti noir, Paris, Asphalte éditions, 2012, pp. 301.

1 Haïti noir è una raccolta di diciotto racconti pubblicata per la prima volta nel 2011 presso l'editore Akashic Books all'interno di «Noir», una collezione che si propone di riunire storie senza un lieto fine, dall'atmosfera sinistra o criminosa, ambientate in un luogo stabilito dal titolo del volume. In questo caso, si tratta appunto di Haiti, colta nei suoi molteplici aspetti. Troviamo la capitale Port-au-Prince (rappresentata da otto quartieri), ma la panoramica si allarga anche a Gokal, Ozanana, Ville Rose, Kenscoff, Croix-des-Bouquets, Saint-Marc, Gonaïves, Morne Haut du Cap e Cap Haïtien. Le località vengono esplicitate accanto al titolo del racconto per sottolineare l'ampia prospettiva presa in considerazione. Il volume risulta particolarmente interessante anche per l'eterogeneità degli scrittori coinvolti nel progetto: molti di loro vivono ad Haiti, altri risiedono all'estero e due autori, Mark Kurlansky e Madison Smartt Bell, pur essendo americani, sono stati scelti perché hanno dedicato numerose pubblicazioni all'isola caraibica.

2 Nella prefazione, Edwidge Danticat spiega che il termine "noir" si addice bene ad Haiti perché ricorda la gloriosa rivoluzione che ha condotto il paese ad essere la prima colonia nera indipendente. Per quanto riguarda il genere letterario a cui la collana fa riferimento, occorre riconoscere che l'ambiente haitiano è particolarmente adatto alla creazione di trame poliziesche. Nell'isola sono frequenti le tensioni familiari, le lotte di rivendicazione sociale, i rapimenti e gli atti criminali. Gli scrittori hanno, quindi, messo alla prova le loro abilità per creare storie "noir" in cui i loro personaggi si trovano ad affrontare la dura realtà sociale, la corruzione, le pessime condizioni igienico-sanitarie e il sistema di disuguaglianza in essere nel paese. L'aspetto che, tuttavia, emerge con forza, è la voglia di vivere e il rifiuto dell'autocommiserazione. Il coraggio, la capacità di cavarsela in ogni situazione, l'ingegnosità sono le caratteristiche principali di questo 
popolo abituato a combattere e a rialzare la schiena dopo ogni calamità naturale. La prova più dura è stata senz'altro il terribile terremoto che il 12 gennaio 2010 ha provocato trecentomila morti e oltre un milione di senzatetto. Danticat ci ricorda che è stata definita come la peggiore catastrofe naturale che ha colpito Haiti negli ultimi due secoli. Il progetto che riguarda la creazione del volume era stato concepito all'inizio del 2009 quando Haiti versava già in estrema povertà. Il sisma ha leggermente cambiato $i$ piani: tre autori hanno incentrato il loro racconto proprio sul terremoto e molti altri alludono alle numerose perdite umane e materiali che ne sono seguite. La voglia di vivere e il coraggio di ripartire sono altresì legati all'immenso patrimonio orale dei Caraibi, alle tradizioni e ai riti magico-religiosi che da sempre costituiscono un valido supporto per la popolazione.

3 Il volume è suddiviso in tre parti in base all'argomento proposto dai racconti: «Magie noire», legata alle pratiche occulte, «Troubles», la sezione più cupa della raccolta perché fornisce un'immagine tenebrosa dell'isola, «Noir sur blanc», rappresentazione dell'universo del compromesso. Oltre ai già citati Madison Smartt Bell e Mark Kurlansky, sono stati coinvolti: Patrick Sylvain, Michèle-Jessica Fièvre, Gary Victor, Kettly Mars, Évelyne Trouillot, Edwidge Danticat, Ibi Aanu Zoboi, Josephat-Robert Large, Marie Lily Cerat, Louis-Philippe Dalembert, Marvin Victor, Katia D. Ulysse, Nadine Pinede, Yanick Lahens, Marie Ketsia Theodore-Pharel e Rodney Saint-Éloy.

È prevista la pubblicazione di un secondo volume di Haiti noir per gennaio 2014 nel quale verranno raccolti i racconti di alcuni dei maggiori scrittori haitiani di tutti i tempi. Una sorta di antologia di classici che introdurrà il lettore alla scoperta della ricca letteratura haitiana. 